\title{
Heat Susceptibility Indices in Bread Wheat (Triticum aestivum L.em Thell) for Yield and Related Attributes
}

\author{
Asaye Demelash Limenie ${ }^{1 *}$, D. K. Gothwal ${ }^{1}$, M. L. Jakhar ${ }^{1}$, \\ A. C. Shivran ${ }^{1}$ and G. K. Mittal ${ }^{1}$ \\ ${ }^{1}$ Department of Plant Breeding and Genetics \\ S.K.N. Agriculture University, Jobner, Rajasthan, India \\ *Corresponding author
}

Keywords

Bread wheat,

Genotypes, Yield,

heat susceptibility

index (HSI), Heat

stress

Article Info

Accepted:

26 January 2021

Available Online:

10 February 2021
The present investigation was carried out to recognize the impact of high temperature on yield and its attributing traits and to select heat stress tolerant parents and cross combinations for future breeding programme in wheat. To achieve the prerequisite of this objective, an experiment was conducted in two environments under normal and heat stress; it involved eight diverse genotypes as parents and their $28 \mathrm{~F}_{1}$ 's. The heat susceptibility indices of parents and crosses for different quantitative characters were determined and genotypes were classified arbitrarily in to four different categories i.e. highly heat tolerant, heat tolerant, moderately heat tolerant and heat susceptible. Based on HSI the parents Raj 3777, Raj 3765 and Raj 4238 were found most desirable for most of the characters under heat stress environment. Among the crosses, Raj 4238 x PBW 550, Raj 4238 x WH 1021, PBW 550 x WH 1021, PBW 343 x Raj 3777, PBW 343 x Raj 4238, PBW 502 x HD 3086, PBW 502 x Raj 4238, PBW 502 x PBW 550, Raj 3777 x Raj 3765, Raj 3777 x Raj 4238, Raj 3777 x WH 1021 and Raj 3765 x WH 1021 were found most suitable as they attained top ranks for more than two yield contributing characters and could be utilized as a promising breeding material for the development of new set of thermal stress tolerant wheat varieties.

\section{Introduction}

Wheat is most widely and principal cultivated food crop in most areas of the world among the cereal crops (Dutamo et al., 2015). It is highly self-pollinated crop with minimum cross pollination ranges from 0.5 to 1.0 per cent. Wheat is a polyploidy series of genetic origin and its species of Triticum and their close relatives can be divided into diploid ( $2 \mathrm{n}$
$=2 \mathrm{x}=14 ; \mathrm{AA})$, tetraploid $(2 \mathrm{n}=4 \mathrm{x}=28$; $\mathrm{AABB})$ and hexaploid $(2 \mathrm{n}=6 \mathrm{x}=42$; AABBDD), in which the basic chromosome number $\mathrm{x}=7$. Wheat is the leading grain crop in the temperate climates of the world. In India, wheat is grown during winter season with an output of 102.20 million tonnes and an average productivity of $3458 \mathrm{~kg} / \mathrm{ha}$ having an area of about 29.55 million hectares (Anonymous, 2019). The area and production 
of wheat in Rajasthan during 2019-20 was reported as 3.49 million hectares and 13.88 million tonnes, respectively with an average productivity of $3971 \mathrm{~kg} / \mathrm{ha}$ (Anonymous, 2020).

Wheat production is significantly affected by abiotic stresses especially at high temperature after anthesis period or during the grain filling stage (Zhang et al., 2017).High temperature is one of the major constraints for production and productivity of wheat. Heat stress during crop growing period, predominantly at germination and grain filling stages restricts wheat production and productivity (Monu Kumar et al., 2013).Different genotypes within a plant species have an optimum range of temperature required for its growth and development between $18-24^{\circ} \mathrm{C}$. Different stages of wheat growth have different optima such as $20-25^{\circ} \mathrm{C}$ for germination, $16-20^{\circ} \mathrm{C}$ for tillering and $20-23^{0} \mathrm{C}$ for grain formation and development. The best vegetative and reproductive growth stage for wheat plant is between $18-22^{\circ} \mathrm{C}$ (Reynolds et al., 2010). As recommended by World Bank estimate, a $2^{\circ} \mathrm{C}$ rise in world average temperature may lead to an extreme heat condition. Because of this reason, 6-20\% losses per degree rise in temperatures were estimated in South Asia (Mondal et al., 2013; Lobell et al., 2008).High temperature stress is resulted of increase in temperature above a threshold level for a period of time which may cause to influence permanent injury to plant growth and physiological development (Wahid et al., 2007; Sareen et al., 2015). Even though short periods of 5-6 days of exposure of temperatures at a range of $28-32^{\circ} \mathrm{C}$, yield of wheat crop reduced up to $15-20$ per cent (Rane et al., 2007; Qin et al., 2008). Consequently existence and growth of crop plants under stress depend on different stress features, such as its severity, duration, number of exposures, combination of stresses and also plant characteristics such as structure, genotype and growth stages (Farooqet al., 2009). As under late sown conditions, the assimilate supply becomes a limiting factor due to increase in temperature during grain development phase due to rapid senescence of the assimilatory surface. It can be emphatically felt that the important characteristics of a high yielding genotype under high temperature are the proper assimilation of the supply of a significant amount of biomass production, with a high to medium grain growth rate and low heat susceptibility indices and this should be considered in the breeding programme for the selection of genotypes for high temperature stress conditions (Sarkar et al., 2001). The present study was carried out to identify heat stress tolerant wheat genotypes for yield and its contributing traits to be used in future breeding programme.

\section{Materials and Methods}

The experimental materials consisting of eight genotypes selected on the basis of broad range of genetic diversity for major yield components, heat tolerance and their suitability for different yield traits, were crossed in half diallel fashion resulting in $28 \mathrm{~F}_{1}$ 's during the year 2018-19. The eight genotypes namely, PBW343, PBW502, Raj3777, Raj3765, HD3086, Raj4238, PBW550 and WH1021along with their 28 $F_{1}$ 's were evaluated in two environments i.e. normal and heat stress with three replications in a RBD during Rabi 2019-20. The heat stress environment was created by manipulating date of sowing. In order to create heat stress at post anthesis stage, the sowing was delayed by about four weeks later than the normal sowing. Parents and $\mathrm{F}_{1}$ 's were represented by a plot of two rows each. Rows were planted in $2.5 \mathrm{~m}$ length spaced at $30 \mathrm{~cm}$ with $10 \mathrm{~cm}$ interplant distance under both the environments. The observations were recorded on ten randomly selected 
competitive plants from each plot in each replication in case of parents and $\mathrm{F}_{1}$ 's in two environments separately on six distinct quantitative characters viz; productive tillers/plant, flag leaf area, spike length, grains/spike, 1000-grain weight and grain yield/plant. However, observation on 1000grain weight was recorded on plot basis. The data obtained were subjected to statistical analysis as per standard procedures.

Mean values of selected plants were used for determining heat susceptibility index. Heat susceptibility index was calculated for grain yield and its attributes by using the formula as suggested by Fisher and Maurer (1978).

$\mathrm{HSI}=\left[1-\mathrm{Y}_{\mathrm{D}} / \mathrm{Y}_{\mathrm{P}}\right] / \mathrm{D}$

Where,

$\mathrm{Y}_{\mathrm{D}}=$ mean of the genotype in heat stress environment

$\mathrm{Y}_{\mathrm{P}}=$ mean of the genotype under normal environment

$\mathrm{D}=$ Heat stress intensity

$\mathrm{D}=1$-[mean of all genotypes in stress environment/mean of all genotypes in normal environment]

\section{Results and Discussion}

Wheat breeding programme aimed at selecting genotypes with high temperature stress tolerance is one of the most vital objectives for wheat breeders. Munjal and Dhanda (2016) used heat susceptible index to screen wheat genotypes tolerant to drought condition. The genotypes with high positive HSI values are susceptible to higher temperature whereas lower values are tolerant for heat as per magnitude of index. In the present study, genotypes were classified in to four different categories arbitrarily i.e. highly heat tolerant (HSI < 0.50), heat tolerant (HSI: 0.51-0.75), moderately heat tolerant (HSI: $0.76-1.00)$ and heat susceptible (HSI > 1.00).
The results of present investigation demonstrated that in comparison to normal sown $\left(E_{1}\right)$, mean performance of parents and $F_{1}$ 's declined under heat stress condition (Table 1). The mean values of grain yield per plant were reduced by $20.66 \%$ and $25.37 \%$ among the parents and $\mathrm{F}_{1}$ 's, respectively under heat stress condition. The results are in agreement with Singh et al., (2011), Sharma et al., (2013), Kavita et al., (2016) and Bhardwaj et al., (2017).Terminal heat stress affected growth and development at the reproductive stage and decreased kernel weight and kernel number (Shefazeadeh et al., 2012) and prolonged exposure to heat could reduce yield and grain quality (Shefazeadeh et al., 2012; Mohammadi et al., 2012). In either responsive genotype, yield loss in grain yield due to terminal heat stress under late sown condition could otherwise be highest in the genotypes recommended for timely sown condition. The selection of wheat genotypes with better grain yield and tolerance is therefore, the main objective of the high-temperature tolerance breeding programme in wheat.

On the basis of HSI (Table 2), it appeared that the genotypes PBW 502 and Raj 4238 for productive tiller per plant; Raj 3777, Raj 3765, HD 3086and WH 1021 for flag leaf area; Raj 3777, HD 3086, Raj 3765 and PWB 343 for spike length; Raj 4238, PBW 502 and PBW 550 for grains per spike; Raj 3777, PBW 550, Raj 3765 and PBW 343 for 1000grain weight and Raj 4238, PBW 550 and PBW 343 for grain yield per plant were least affected under heat stress. An overall assessment of parents indicated that Raj 4238, Raj 3777, Raj 3765 and PBW 343 were found to be desirable for the grain yield and most of its attributes. Among 28 F 's crosses, Raj 3777 x Raj 3765, Raj 3777 x WH 1021, Raj $4238 \times$ PBW 550, PBW502 x HD 3086 and Raj 3765 x WH 1021 for productive tiller per plant; PBW 343 x Raj 3765, Raj 4238 x WH 
1021, Raj 3765 x Raj 4238, Raj 4238 x PBW 550 and PBW $550 \times$ WH 1021 for flag leaf area; Raj 4238 x PBW 550, Raj 3777 x HD 3086, PBW 502 x WH 1021, PBW 343 x Raj 4238 and PBW 343 x Raj 3777 for spike length; PBW 502 x WH 1021, HD 3086 x Raj 4238, PBW 502 x Raj 4238, PBW $343 \times$ PBW 502 and PBW $343 \times$ WH 1021 for grains per spike; HD 3086 x WH 1021, PBW 502 x Raj 3765, Raj 3765 x PBW 550, Raj $4238 \times$ PBW550 and PBW 502 x Raj 4238 for 1000-grain weight and PBW 502 x WH 1021, HD 3086 x Raj 4238, PBW 502 x Raj 4238, PBW $550 \times$ WH 1021 and Raj 3777 x PBW 550for grain yield per plant exhibited comparatively more tolerance under heat stress environment.

In the case of grain yield per plant, the results revealed that among the parents in general, Raj 3777, Raj 3765 and Raj 4238 were least affected and similarly the crosses viz., PBW 502 x WH 1021, HD 3086 x Raj 4238, PBW 502 x Raj 4238, PBW 550 x WH 1021 and Raj 3777 x PBW 550 were considered as desirable for heat stress tolerance under late sowing condition. The crosses namely, Raj4238 x PBW550, Raj4238 x WH1021, PBW550 x WH1021, PBW343 x Raj3777, PBW343 x Raj4238, PBW502 x HD3086, PBW502 x Raj4238, PBW502 x WH 1021, Raj3777 x Raj3765, HD 3086 x Raj4238, Raj3777 x WH1021 and Raj3765 x WH1021 showed the superiority for most of the yield attributing traits under heatstress condition. But particularly parents, Raj4238 and PBW550 and from the crosses PBW502 $x$ WH1021and HD3086 x Raj4238 showed HSI value less than 0.50 and were least affected under heatstress condition for grain yield per plant while among the crosses, PBW502 x Raj4238 and PBW550 x WH1021 revealed HSI value $0.50-0.75$, therefore, these crosses were considered as heat tolerant.
Low magnitude of heat stress intensity (Dvalue) i.e. less than 0.20 , indicated that the parameters flag leaf area (0.08), spike length (0.13), grains/spike (0.05), 1000-grain weight (0.17)showed more tolerance whereas productive tillers/plant (0.36) and grain yield/plant (0.24) with high heat stress intensity (D-value) i.e. 0.21 to 0.50 , suffered more under heat stress environment. Similar findings were also observed by Singh et al., (2011); Bhardwaj et al., (2017) and kumar et al., (2018). The extent of genetic diversity is therefore, a prerequisite for selecting and enhancing heat tolerance (Sharma et al., 2014). The spatial diversity of heat tolerance could also help to provide beneficial alleles for heat tolerance improvement and potential output (Sun et al., 2013). Therefore, identification of heat tolerant genotypes for different traits linked to heat stress at different stages of plant growth may help to combine heat tolerant traits in the desired sense. These parents should be further exploited for improvement of grain yield under late and very late sown conditions.

Summary and conclusion are as follows:

In the present study, on the basis of HSI, the parents Raj 4238, Raj 3777, Raj 3765 and PBW 343 were most desirable under heat stress environment as they attained high HSI values for yield and its attributing traits. Similarly, the crosses Raj 4238 x PBW 550, Raj 4238 x WH 1021, PBW 550 x WH 1021, PBW 343 x Raj 3777, PBW 343 x Raj 4238, PBW 502 x HD 3086, PBW 502 x Raj 4238, PBW 502 x WH 1021, Raj 3777 x Raj 3765, HD 3086 x Raj 4238, Raj 3777 x WH 1021 and Raj 3765 x WH 1021were found most desirable as they attained top ranks for more than two characters. It is recommended that these genotypes may perform as potential donor for heat tolerance. 
Table.1 Mean values of parents and $\mathrm{F}_{1}$ 's for productive tillers/plant, flag leaf area, spike length, grains/spike, 1000-grain weight and grain yield/plant

\begin{tabular}{|c|c|c|c|c|c|c|c|c|c|c|c|c|}
\hline \multirow[t]{2}{*}{ Genotypes/Crosses } & \multicolumn{2}{|c|}{$\begin{array}{l}\text { Productive } \\
\text { tillers/plant }\end{array}$} & \multicolumn{2}{|c|}{$\begin{array}{l}\text { Flag leaf area } \\
\left(\mathrm{cm}^{2}\right)\end{array}$} & \multicolumn{2}{|c|}{ Spike length $(\mathrm{cm})$} & \multicolumn{2}{|c|}{ Grains/spike } & \multicolumn{2}{|c|}{$\begin{array}{l}\text { 1000-grain } \\
\text { weight }\end{array}$} & \multicolumn{2}{|c|}{$\begin{array}{c}\text { Grain } \\
\text { yield/plant (g) }\end{array}$} \\
\hline & $\mathrm{E}_{1}$ & $\mathrm{E}_{2}$ & $\mathrm{E}_{1}$ & $\mathrm{E}_{2}$ & $\mathrm{E}_{1}$ & $\mathrm{E}_{2}$ & $\mathrm{E}_{1}$ & $\mathrm{E}_{2}$ & $\mathrm{E}_{1}$ & $\mathrm{E}_{2}$ & $\mathrm{E}_{1}$ & $\mathrm{E}_{2}$ \\
\hline PBW 343 & 7.47 & 3.30 & 17.82 & 16.31 & 8.47 & 7.77 & 43.37 & 41.40 & 48.03 & 43.11 & 20.65 & 17.32 \\
\hline PBW 502 & 6.40 & 4.27 & 24.45 & 16.48 & 9.18 & 7.73 & 39.93 & 43.13 & 57.03 & 37.93 & 19.10 & 15.65 \\
\hline Raj 3777 & 8.77 & 4.30 & 36.85 & 37.97 & 9.70 & 9.93 & 48.03 & 40.43 & 46.90 & 38.95 & 25.09 & 17.90 \\
\hline Raj 3765 & 6.83 & 4.00 & 35.96 & 38.41 & 9.88 & 9.50 & 49.30 & 42.90 & 51.65 & 46.53 & 26.02 & 18.57 \\
\hline HD 3086 & 6.60 & 3.30 & 18.66 & 27.73 & 8.58 & 8.67 & 39.20 & 35.87 & 45.49 & 37.96 & 19.32 & 13.28 \\
\hline Raj 4238 & 6.30 & 4.07 & 26.63 & 27.95 & 7.72 & 7.08 & 36.00 & 43.93 & 55.69 & 43.04 & 15.65 & 18.02 \\
\hline PBW 550 & 6.67 & 3.13 & 29.47 & 31.66 & 9.03 & 8.12 & 45.90 & 47.37 & 45.41 & 43.56 & 19.63 & 17.64 \\
\hline WH 1021 & 7.57 & 3.90 & 32.07 & 35.77 & 10.32 & 7.63 & 48.20 & 42.33 & 48.89 & 37.37 & 23.02 & 15.28 \\
\hline PBW 343 x PBW 502 & 6.67 & 4.37 & 20.42 & 20.65 & 9.77 & 8.33 & 41.53 & 44.67 & 49.23 & 41.10 & 20.09 & 16.18 \\
\hline PBW 343 x Raj 3777 & 8.07 & 4.50 & 25.27 & 21.59 & 9.95 & 9.23 & 51.37 & 50.87 & 51.64 & 40.35 & 24.55 & 19.99 \\
\hline PBW 343 x Raj 3765 & 7.10 & 4.90 & 25.55 & 31.10 & 9.47 & 8.23 & 49.57 & 43.43 & 54.33 & 43.39 & 27.04 & 18.07 \\
\hline PBW 343 x HD 3086 & 8.80 & 4.03 & 28.59 & 18.64 & 10.17 & 8.37 & 52.67 & 48.93 & 52.07 & 39.67 & 28.82 & 18.68 \\
\hline PBW $343 \times$ Raj 4238 & 6.87 & 4.63 & 29.33 & 25.13 & 10.20 & 9.47 & 47.47 & 46.13 & 51.02 & 42.39 & 25.57 & 19.06 \\
\hline PBW 343 x PBW 550 & 6.57 & 4.57 & 33.01 & 18.26 & 9.85 & 8.83 & 52.77 & 48.70 & 51.52 & 41.29 & 27.39 & 19.91 \\
\hline PBW 343 x WH 1021 & 6.93 & 4.47 & 29.76 & 20.18 & 9.10 & 7.92 & 42.10 & 43.63 & 43.44 & 37.01 & 21.26 & 15.75 \\
\hline PBW 502 x Raj 3777 & 8.23 & 5.77 & 29.54 & 19.07 & 10.23 & 8.73 & 53.53 & 47.00 & 52.23 & 41.59 & 30.30 & 17.87 \\
\hline PBW 502 x Raj 3765 & 6.83 & 4.17 & 25.36 & 21.55 & 9.77 & 6.30 & 48.13 & 35.07 & 50.57 & 47.88 & 24.27 & 15.16 \\
\hline PBW 502 x HD 3086 & 7.37 & 6.20 & 28.73 & 26.47 & 9.92 & 8.90 & 50.87 & 42.00 & 55.31 & 41.88 & 26.93 & 16.94 \\
\hline PBW 502 x Raj 4238 & 7.07 & 4.17 & 27.69 & 27.80 & 9.30 & 8.27 & 43.60 & 48.83 & 52.16 & 46.52 & 22.58 & 19.12 \\
\hline PBW 502 x PBW 550 & 6.83 & 4.67 & 30.98 & 28.72 & 9.78 & 8.80 & 52.87 & 48.40 & 52.19 & 38.63 & 24.99 & 18.17 \\
\hline PBW 502 x WH 1021 & 8.20 & 5.63 & 25.34 & 21.58 & 9.30 & 9.07 & 43.40 & 50.10 & 48.93 & 41.69 & 21.22 & 20.29 \\
\hline Raj 3777 x Raj 3765 & 7.03 & 7.10 & 28.67 & 27.47 & 10.30 & 9.23 & 47.67 & 47.97 & 48.31 & 40.67 & 25.75 & 19.04 \\
\hline Raj 3777 x HD 3086 & 8.13 & 6.33 & 38.72 & 37.39 & 10.42 & 10.17 & 57.27 & 51.87 & 52.41 & 40.59 & 26.94 & 19.30 \\
\hline Raj 3777 x Raj 4238 & 7.47 & 4.73 & 33.53 & 36.76 & 10.55 & 9.43 & 51.40 & 49.67 & 47.25 & 35.60 & 24.26 & 17.28 \\
\hline Raj 3777 x PBW 550 & 8.97 & 5.50 & 35.76 & 33.28 & 9.87 & 7.67 & 47.20 & 46.50 & 46.88 & 38.35 & 21.87 & 17.53 \\
\hline Raj 3777 x WH 1021 & 7.10 & 6.10 & 36.18 & 29.45 & 10.77 & 9.17 & 57.97 & 42.47 & 47.59 & 38.04 & 27.18 & 18.23 \\
\hline Raj 3765 x HD 3086 & 8.63 & 5.40 & 34.32 & 19.14 & 11.22 & 7.73 & 50.17 & 45.53 & 54.47 & 42.32 & 25.56 & 18.94 \\
\hline Raj 3765 x Raj 4238 & 7.80 & 4.83 & 26.52 & 31.26 & 9.93 & 7.77 & 48.43 & 44.63 & 53.24 & 44.72 & 24.56 & 18.15 \\
\hline Raj 3765 x PBW 550 & 7.70 & 4.70 & 32.42 & 24.68 & 9.98 & 8.23 & 43.40 & 42.27 & 47.45 & 44.51 & 21.70 & 17.16 \\
\hline Raj 3765 x WH 1021 & 6.23 & 5.17 & 34.04 & 27.43 & 10.02 & 8.88 & 49.40 & 48.70 & 48.07 & 43.09 & 25.55 & 20.23 \\
\hline HD 3086 x Raj 4238 & 7.70 & 4.43 & 33.38 & 29.23 & 10.85 & 8.77 & 40.50 & 46.13 & 53.24 & 43.21 & 20.41 & 18.62 \\
\hline HD 3086 x PBW 550 & 7.77 & 5.07 & 29.75 & 27.28 & 9.77 & 7.57 & 48.30 & 44.87 & 51.59 & 42.64 & 23.54 & 18.59 \\
\hline HD 3086 x WH 1021 & 7.03 & 3.87 & 29.80 & 17.42 & 10.67 & 9.63 & 51.80 & 41.57 & 47.80 & 45.37 & 24.17 & 18.15 \\
\hline Raj 4238 x PBW 550 & 5.60 & 4.73 & 29.20 & 34.13 & 9.35 & 9.38 & 45.17 & 43.77 & 48.87 & 43.56 & 21.43 & 17.40 \\
\hline Raj 4238 x WH 1021 & 7.70 & 4.97 & 28.17 & 33.39 & 9.40 & 8.28 & 45.80 & 45.67 & 51.41 & 41.70 & 22.89 & 17.43 \\
\hline PBW $550 \times$ WH 1021 & 7.57 & 3.83 & 31.61 & 36.83 & 9.75 & 7.33 & 43.90 & 45.27 & 51.63 & 43.50 & 23.20 & 19.09 \\
\hline PM & 7.07 & 3.78 & 27.74 & 29.04 & 9.11 & 8.30 & 43.74 & 42.17 & 49.89 & 41.06 & 21.06 & 16.71 \\
\hline FM & 7.43 & 4.96 & 30.06 & 26.64 & 9.99 & 8.56 & 48.51 & 45.88 & 50.53 & 41.83 & 24.43 & 18.23 \\
\hline GM & 7.35 & 4.70 & 29.54 & 27.17 & 9.79 & 8.50 & 47.45 & 45.06 & 50.39 & 42.08 & 23.68 & 17.89 \\
\hline SE & 0.38 & 0.23 & 1.82 & 1.68 & 0.34 & 0.41 & 1.56 & 1.15 & 1.93 & 1.73 & 1.02 & 0.57 \\
\hline CD5 & 1.06 & 0.66 & 5.13 & 4.75 & 0.96 & 1.16 & 4.39 & 3.24 & 5.44 & 4.87 & 2.89 & 1.60 \\
\hline CD1 & 1.41 & 0.87 & 6.81 & 6.31 & 1.27 & 1.54 & 5.83 & 4.30 & 7.22 & 6.47 & 3.83 & 2.13 \\
\hline CV\% & 9.14 & 8.79 & 10.99 & 11.15 & 6.18 & 8.57 & 5.85 & 4.53 & 6.81 & 7.36 & 7.69 & 5.64 \\
\hline
\end{tabular}


Table.2 HSI for productive tiller/plant, flag leaf area, spike length, grains/spike, 1000-grain weight and grain yield per plant in heat stress against to normal environment

\begin{tabular}{|c|c|c|c|c|c|c|}
\hline Parents/Crosses & $\begin{array}{l}\text { Productive } \\
\text { tillers/plant }\end{array}$ & $\begin{array}{l}\text { Flag leaf } \\
\text { area }\left(\mathrm{cm}^{2}\right)\end{array}$ & $\begin{array}{l}\text { Spike length } \\
\text { (cm) }\end{array}$ & Grains /spike & $\begin{array}{l}\text { 1000- grain } \\
\text { weight }(g)\end{array}$ & $\begin{array}{l}\text { Grain yield } \\
\text { /plant (g }\end{array}$ \\
\hline PBW 343 & 1.55 & 1.06 & 0.63 & 0.90 & 0.59 & 0.66 \\
\hline PBW 502 & 0.92 & 4.06 & 1.20 & -1.59 & 1.93 & 0.74 \\
\hline Raj 3777 & 1.41 & -0.38 & -0.18 & 3.14 & 0.98 & 1.17 \\
\hline Raj 3765 & 1.15 & -0.85 & 0.29 & 2.57 & 0.57 & 1.17 \\
\hline HD 3086 & 1.38 & -6.06 & -0.07 & 1.69 & 0.96 & 1.28 \\
\hline Raj 4238 & 0.98 & -0.62 & 0.62 & -4.37 & 1.31 & -0.62 \\
\hline PBW 550 & 1.47 & -0.93 & 0.77 & -0.63 & 0.24 & 0.42 \\
\hline WH 1021 & 1.34 & -1.44 & 1.98 & 2.41 & 1.36 & 1.38 \\
\hline $\begin{array}{l}\text { PBW } 343 \times \text { PBW } \\
502\end{array}$ & 0.96 & -0.14 & 1.12 & -1.50 & 0.95 & 0.79 \\
\hline PBW 343 x Raj 3777 & 1.22 & 1.82 & 0.55 & 0.19 & 1.26 & 0.76 \\
\hline PBW 343 x Raj 3765 & 0.86 & -2.71 & 0.99 & 2.45 & 1.16 & 1.36 \\
\hline PBW 343 x HD 3086 & 1.50 & 4.33 & 1.35 & 1.41 & 1.37 & 1.44 \\
\hline PBW 343 x Raj 4238 & 0.90 & 1.78 & 0.55 & 0.56 & 0.98 & 1.04 \\
\hline $\begin{array}{l}\text { PBW } 343 \times \text { PBW } \\
550\end{array}$ & 0.84 & 5.56 & 0.78 & 1.53 & 1.15 & 1.12 \\
\hline $\begin{array}{l}\text { PBW } 343 \times \text { WH } \\
1021\end{array}$ & 0.99 & 4.01 & 0.99 & -0.72 & 0.85 & 1.06 \\
\hline PBW 502 x Raj 3777 & 0.83 & 4.41 & 1.11 & 2.42 & 1.18 & 1.68 \\
\hline PBW $502 \times$ Raj 3765 & 1.08 & 1.87 & 2.70 & 5.38 & 0.31 & 1.53 \\
\hline PBW 502 x HD 3086 & 0.44 & 0.98 & 0.78 & 3.46 & 1.40 & 1.52 \\
\hline PBW 502 x Raj 4238 & 1.14 & -0.05 & 0.84 & -2.38 & 0.62 & 0.63 \\
\hline $\begin{array}{l}\text { PBW } 502 \times \text { PBW } \\
550\end{array}$ & 0.88 & 0.91 & 0.76 & 1.67 & 1.50 & 1.12 \\
\hline $\begin{array}{l}\text { PBW } 502 \times \text { WH } \\
1021\end{array}$ & 0.87 & 1.85 & 0.19 & -3.06 & 0.85 & 0.18 \\
\hline Raj 3777 x Raj 3765 & 0.01 & 0.52 & 0.79 & -0.12 & 0.91 & 1.06 \\
\hline Raj 3777 x HD 3086 & 0.61 & 0.43 & 0.18 & 1.87 & 1.30 & 1.16 \\
\hline Raj 3777 x Raj 4238 & 1.01 & -1.20 & 0.80 & 0.67 & 1.42 & 1.18 \\
\hline Raj 3777 x PBW 550 & 1.07 & 0.86 & 1.69 & 0.29 & 1.05 & 0.81 \\
\hline Raj 3777 x WH 1021 & 0.39 & 2.32 & 1.13 & 5.30 & 1.16 & 1.35 \\
\hline Raj 3765 x HD 3086 & 1.04 & 5.51 & 2.36 & 1.83 & 1.29 & 1.06 \\
\hline Raj 3765 x Raj 4238 & 1.05 & -2.22 & 1.66 & 1.56 & 0.92 & 1.07 \\
\hline Raj 3765 x PBW 550 & 1.08 & 2.97 & 1.33 & 0.52 & 0.36 & 0.86 \\
\hline Raj 3765 x WH 1021 & 0.47 & 2.42 & 0.86 & 0.28 & 0.60 & 0.85 \\
\hline HD 3086 x Raj 4238 & 1.17 & 1.55 & 1.46 & -2.76 & 1.09 & 0.36 \\
\hline HD 3086 x PBW 550 & 0.96 & 1.03 & 1.71 & 1.41 & 1.00 & 0.86 \\
\hline HD 3086 x WH 1021 & 1.25 & 5.17 & 0.74 & 3.92 & 0.29 & 1.02 \\
\hline Raj 4238 x PBW 550 & 0.43 & -2.10 & -0.03 & 0.61 & 0.63 & 0.77 \\
\hline Raj $4238 \times$ WH 1021 & 0.98 & -2.31 & 0.90 & 0.06 & 1.09 & 0.97 \\
\hline $\begin{array}{l}\text { PBW } 550 \times \text { WH } \\
1021\end{array}$ & 1.37 & -2.05 & 1.88 & -0.62 & 0.91 & 0.73 \\
\hline D- value & 0.36 & 0.08 & 0.13 & 0.05 & 0.17 & 0.24 \\
\hline
\end{tabular}




\section{Acknowledgement}

The author is extremely acknowledged to the department of Plant Breeding and Genetics, S.K.N. Agriculture University, Jobner (Rajasthan) for supporting the research facilities and Indian Council of Agricultural Research for providing scholarship fund.

\section{References}

Anonymous. 2019. Foreign Agricultural Service/USDA (United States Department of Agriculture), Office of Global Analysis.

Anonymous. 2020. Agriculture Statistics. Government of Rajasthan, Department of agriculture.

Bhardwaj, R., Sharma, A., Singh, H. and Sharma, B.K. 2017.Determination of heat susceptibility indices for some quantitative traits in bread wheat (Triticum aestivum L. em. Thell.), International Journal of Pure and Applied Bioscence, 5(2): 230-239.

Dutamo, D., Alamerew, S., Eticha, F., and Assef, E. 2015. Genetic Variability in Bread Wheat (Triticum aestivum L.) Germplasm for Yield and Yield Component Traits.Journal of Biology, Agriculture and Healthcare, 5(17):140147.

Farooq, M., Wahid, A., and Kobayashi, N. 2009. Plant drought stress: effects, mechanisms and management. Agronomy of Sustainable Development, 29:185-212.

Fisher, R. A. and Maurer, R. 1978. Drought resistance in spring wheat cultivars I. Grain yield responses. Australia Journal of Agriculture Research, 29 (5): 897- 912.

Kavita, Munjal, R., Kumar, N. and Dhanda, S.S. 2016. Stress response behavior in different wheat species in relation to heat tolerance. Journal of Wheat
Research, 8(2):49-53

Kumar, P., Singh, H., Singh, J and Choudhary, R.N. 2018. Estimation of heat stress tolerance for yield and its contributing attributes in bread wheat. International Journal of Current Microbiology Applied Science, 7(7): 3817-3825

Lobell, D.B, Burke, M. B. and Tebaldi, C. 2008. Prioritizing climate change adaptation needs for food security in 2030. Science 319:607-610.

Mohammadi, M., Karimizadeh, R. and Shefazeadeh, M. K. 2012. Grain yield performance of bread wheat germplasm under heat and drought field conditions. Annual Biology Research, 3:3149-3155.

Mondal, S., Singh, R. P. and Crossa, J. 2013. Earliness in wheat: a key to adaptation under terminal and continual high temperature stress in South Asia. Field Crop Res, 151:19-26.

Monu Kumar, M., Sharma, R.K., Kumar, P., Singh, G.P., Sharma, J.B. and Gajghate, R. 2013. Evaluation of bread wheat (Triticum aestivum L.) genotypes for terminal heat tolerance under different environments. Indian Journal of Genetics and Plant Breeding, 73(4): 446-449.

Munjal, R. and Dhanda, S.S. 2016. Assessment of drought resistance in Indian wheat cultivars for morphophysiological traits. Ekin Journal of Crop Breeding and Genetics, 2(1): 7481.

Qin, D., Wu, H., Peng, H., Yao, Y., Ni, Z., Li, Z., Zhou, C. and Sun, Q. 2008. Heat stress-responsive transcriptome analysis in heat susceptible and tolerant wheat (Triticum aestivum L.) by using wheat genome array. BMC Genom. 9:432.

Rane, J., Pannu, R. K., Sohu, V. S., Saini, R. S., Mishra, B., Shoran, J., Crossa, M., Vargas, J. and Joshi, A. K. 2007. Performance of yield and stability of 
advanced wheat genotypes under heat stressed environments of Indo-Gangetic plains. Crop Science, 47: 1561-1573.

Reynolds M, Bonnett D, Scott CC, Robert TR, Mane Y, Mather E D, Parr JM. 2010. Raising yield potential of wheat. I. Overview of a consortium approach and breeding strategies. Journal of Experimental Botany, 62 (2): 439-452.

Sareen, S., Kundu, S., Malik, R., Dhillon, O.P. and Singh, S.S. 2015. Exploring indigenous wheat (Triticum aestivum L.) germplasm accessions for terminal heat tolerance. Indian Journal of Agricultural Sciences, 85(2): 194-198.

Sarkar, C.K.G., Srivastava, P.S.L. and Deshmukh, P.S. 2001. Grain growth rate and heat susceptibility index: Traits for breeding genotypes tolerant to terminal high temperature stress in bread wheat (Triticum aestivum L.). Indian Journal of Genetics, 61(3): 209212.

Sharma, A., Rawat, R.S., Verma, J.S. and Jaiswal, J.P. 2013. Correlation and heat susceptibility index analysis for terminal heat tolerance in bread wheat. Journal of Central European Agriculture, 14(2): 535-544.

Sharma, P., Sareen, S., Saini, M., Verma, A., Tyagi, B.S. and Sharma, I. 2014. Assessing genetic variation for heat tolerance in synthetic wheat lines using phenotypic data and molecular markers. Australian journal of crop sciences. 8(4): 515-522.

Shefazeadeh, M. K., Mohammadi, M., Karimizadeh, R. and Mohammadinia G. 2012. Tolerance study on bread wheat genotypes under wheat stress Annual Biology Research, 3:4786-4789.

Singh, K., Sharma, S. N. and Sharma, Y. 2011. Effect of high temperature on yield attributing traits in bread wheat. Bangladesh Journal of Agriculture Research, 36(3): 415-426

Sun, J., Luo, H., Fu, J. and Huang, G. 2013. Classification of genetic variation for drought tolerance in Tall fescue using physiological traits and molecular markers. Crop Science, 53: 647-654.

Wahid. A., Gelani, S., Ashraf, M.M. and Foolad, R. 2007. Heat tolerance in plants: An overview. Environmental of Experimental Botany, 61: 199-223.

Zhang, Y., Pan, J., Huang, X., Huang, X., Guo, D., Lou, H., Hou, Z., Su, M., Liang, R., Xie, C., You, M. and Li, B.2017. Differential effects of a postanthesis heat stress on wheat (Triticum aestivum L.) grain proteome determined by iTRAQ. Scientific Report, 7: 3468.

\section{How to cite this article:}

Asaye Demelash Limenie, D. K. Gothwal, M. L. Jakhar, A. C. Shivran and Mittal, G. K. 2021. Heat Susceptibility Indices in Bread Wheat (Triticum aestivum L. em Thell) for Yield and Related Attributes. Int.J.Curr.Microbiol.App.Sci. 10(02): 3454-3461. doi: https://doi.org/10.20546/ijcmas.2021.1002.381 